\title{
Publicidade Social e sua tipificação: uma metodologia de transformação social
}

\section{Social Advertising and its classification: a social transformation methodology}

Patrícia Gonçalves Saldanhal

Resumo: O objetivo do presente trabalho é argumentar em que medida uma das perspectivas contra-hegemônicas da Publicidade Social Latino-americana, desenvolvida empiricamente, pode ser um terreno fértil, capaz de alimentar a reflexão que contribui para o fortalecimento de uma cidadania participativa com múltiplas vozes. Para tanto, apresentaremos o mapeamento epistemológico desenvolvido durante 6 anos, com a tipificação que demonstrará as derivações que sistematizaram esta vertente da publicidade: afirmativa, comunitária, causa, interesse público e transversal. A abordagem teórica conjugada com a pesquisa-ação fortalece uma metodologia que possibilita o diálogo com uma realidade latino-americana, visto que respeita suas características históricas, culturais e geográficas sem sucumbir às bases teóricas do Norte Global.

Palavras-chave: publicidade social, pesquisa-ação, comunicação comunitária, contra-hegemonia.

\begin{abstract}
This paper aims to examine to which extent the counter-hegemonic perspectives of Latin American Social Advertising empirically developed can be a fertile ground, capable of feeding the reflection that contributes to strengthening a diverse participatory citizenship. In this sense, we present the epistemological mapping developed over six years, with the typification that systematyzes this aspect of advertising: affirmative, community, of cause, of public interest and transversal. The theoretical approach combined with the action research methodology enables dialogue with a Latin American reality, insofar as it respects its
\end{abstract}

1 Universidade Federal Fluminense (UFF). Niterói, Rio de Janeiro, Brasil.

http://orcid.org/0000-0002-7041-129X E-mail: patsaldanha@gmail.com. 
historical, cultural and geographical characteristics without succumbing to the theoretical bases of the Global North.

Keywords: social advertising, action research, community communication, counter-hegemony 


\section{Introdução}

O fortalecimento de práticas cotidianas ligadas à Publicidade Social foi um dos fatores que contribuiu com a veloz reorganização social na última década. Outro fator importante foi a remodelagem dos comportamentos ligados ao consumo que, impelida por esse viés publicitário, resultou em novas formas de participação cidadã e em alternativas de inclusão. Tais mudanças foram impulsionadas por tecnologias digitais que impactaram nos três aspectos estruturantes do campo comunicacional: o vinculativo, o relacional e o crítico-cognitivo (SODRÉ, 2015).

Os aspectos são respectivamente representados, primeiro pela transfiguração da vida ordinária do cidadão comum que passou a publicizar as próprias produções ligadas a questões de ordem pessoal, às iniciativas artísticas, esportivas, inclusive as de comércio independente, como é o caso dos pequenos produtores que passaram a usar as redes sociotécnicas para divulgar suas atividades e comercializar produtos e serviços em âmbito local e, em alguns casos, global (vinculativo). Depois, pelo interesse do mercado que, para possibilitar a veiculação dessas produções, investiu na popularização dos dispositivos móveis como tablets, smartphones entre outros (relacional). Por fim, na esfera acadêmica, as investigações relacionadas à publicidade tomaram novos rumos teórico-metodológicos. Sobretudo, quando as críticas relativas às consequências sociais da práxis publicitária tradicional ecoaram longe, ora por reproduzirem massivamente conteúdos descolados dos interesses sociais, ora por apagarem, em suas produções, particularidades das realidades socioculturais investigadas. Esse conjunto de fatores impulsionou vozes dissonantes da comunicação hegemônica a reivindicar direito de resposta e, consequentemente, a pesquisa em publicidade se reinventou (crítico-cognitivo).

Ficou insustentável manter investigações baseadas em modelos dados, sem considerar as inovações tecnológicas, estéticas, políticas ou sociais. Foi exatamente aí que despontou uma perspectiva peculiar da Publicidade Social ligada à realidade brasileira, pois não há como investigar, por exemplo, casos na América Latina com os mesmos 
princípios que regem a Publicidade Social dos Estados Unidos, da Espanha ou de Portugal. Como diz Barbero, seria o mesmo que "estar falsificando a vida" para que coubesse num modelo (BARBERO; BARCELOS, 2000, p. 154).

Consideremos, portanto, as diferentes visões epistemológicas da $\mathrm{Pu}$ blicidade Social. Por um lado, as correntes do norte global perscrutam o viés do Marketing Social e atendem aos objetivos do cliente anunciante com produções pautadas em temáticas sociais e veiculadas de acordo com a política econômica que favorece os interesses dominantes. Por outro, no sul global, a discussão emerge das pesquisas engajadas às causas dos movimentos sociais e dos direitos humanos, alinhando-se aos preceitos da Comunicação Comunitária.

Isto posto, o objetivo do presente artigo é, inicialmente definir de qual viés da Publicidade Social estamos falando para, em seguida, argumentarmos em que medida a perspectiva contra-hegemônica da publicidade pode ser um terreno fértil capaz de alimentar a reflexão que contribui para o fortalecimento de uma cidadania participativa.

A discussão teórica alicerçará o resgate do sentido originário da publicidade, o de "tornar algo público", para que se verifique como a atividade teve seu sentido reduzido ao aspecto mercadológico. Também sustentará a argumentação contra-hegemônica da publicidade para debater sua atuação nas tipificações apresentadas na síntese conceitual articulada às seguintes esferas da sociedade civil: Comunidades, grupos que compartilham um mesmo ‘comum' física (comunitária) ou virtualmente (afirmativa); Estado (de interesse público); Organizações de cooperação internacional, ONGs e Movimentos Sociais (de causa); e, por fim, Organizações públicas ou privadas (transversal).

Argumentaremos como a pesquisa-ação foi metodologicamente fundamental para a realização de projetos ou análise de casos referentes às derivações expostas: comunitária, afirmativa, de interesse público, transversal. Através de uma pesquisa propositiva do campo comunicacional, pretendemos incrementar a reflexão sobre a Publicidade Social sem reduzi-la ao oposto de publicidade mercantil, já que pode ter aspectos 
comerciais sem, necessariamente, enfraquecer ou anular seu propósito social. É preciso acolher estas novas classificações da publicidade contra-hegemônica que estão por vir, ou que já existam, ainda que não tenham sido identificadas ou enxergadas mercadológica ou academicamente.

\section{Publicidade Social: uma convergência entre a Publicidade e a Comunicação Comunitária}

A presente pesquisa é propositiva e está vinculada a um campo de estudos em permanente mutação ou "renovação de sentido, que ocorre num processo dialógico de interação com a sociedade, lugar da práxis que desenha e redesenha esses sentidos" (BACCEGA, 2010, p. 53). Esta dinâmica está atrelada à "mutação conceitual" que prevê uma hibridização “às velhas formações discursivas” (SODRÉ, 2002, p. 13). Quer dizer, as alterações são continuadas e a "constituição do novo nunca poderá se dar sem que os 'resíduos' do velho estejam presentes” (BACCEGA, 2010, p. 53). Quando determinadas significações que parecem desconexas são mescladas, podem ressignificar olhares originando novas visões capazes de manter o campo em movimento. Um exemplo é a relação entre as concepções de Publicidade e de Comunicação Comunitária que, num primeiro momento, parecem antagônicas, mas podem confluir dependendo do enfoque da Publicidade Social. Como esta articulação ocorre no campo da Comunicação Social, recentemente descrito como uma ciência pós-disciplinar na obra Ciência do Comum (SODRÉ, 2015), passaremos brevemente pelo campo, para chegarmos na discussão sobre o eixo de Publicidade Social que nos interessa.

Muniz Sodré atualiza a estrutura do âmbito comunicativo percebida inicialmente, em Antropológica do Espelho (2000), em três "níveis de atuação" (vivência cotidiana). Com as tecnologias de última geração cada vez mais impregnadas no cotidiano, os níveis passaram a ser compreendidos como "níveis de operação" (gerenciamento da vida). Assim, o que era vinculação, se mantém na ordem vinculativa; já a veiculação, passa a ser relacional e o que era cognição, vira crítico-cognitivo (ou 
metacrítico). Sodré chama a atenção para como a falta de conexão entre os níveis operativos tem gerado dispersão cognitiva em relação às narrativas amplamente propagadas, mesmo quando são incompatíveis com a realidade ou prejudiciais a determinados grupos.

Por conta da vigência de um estágio de apatia coletiva, compreender as atividades comunicacionais apenas pela ótica mercadológica fragiliza o pensamento crítico. O autor pondera sobre os impactos das veiculações nas relações sociais, sejam eles de ordem interpessoal ou crítico-cognitiva. Em outros termos, naturalizar o aspecto relacional no cotidiano pode limitar a capacidade reflexiva do receptor, reduzindo sua compreensão sobre comunicação ao aspecto mecanicista, próprio do paradigma funcionalista norte-americano, berço da Publicidade Social.

Porém, na mesma arena em que o discurso vigente enfatiza a centralidade da instrumentalização com certo tom de neutralidade, emergem narrativas que resistem à ubiquidade de um saber dominante e grupos lutam pela legitimidade de seus modos de fazer e formas de saber. É nesse ringue que crescem as novas vertentes da Publicidade ligadas à Comunicação Comunitária, como o caso da Publicidade Social tratada aqui: a que não é gerenciada por corporações transnacionais e conta com a participação efetiva da sociedade civil. Se uma parte das pesquisas em comunicação se realiza sob o prisma dos efeitos característicos da produção midiática hegemônica propagadora do "comum” a ser absorvido, é premente pensar em novas formas de produção de conhecimento para o campo.

Se o "comum” é o objeto da Comunicação por ser seu centro evolutivo, é fundamental compreender sua origem, produção e circulação. Segundo Sodré (2015), a comunidade é o espaço simbólico onde acontece a comunicação, independentemente do código propalado pela mídia hegemônica. Concomitante à criação e à veiculação massiva do "comum" administrado por organizações mercadológicas de pequeno e médio portes até as grandes corporações transnacionais, o "comum" também é corroborado por sua riqueza simbólica vigente no interior da comunidade. 
Por isso, é o Comum que entra na disputa capitalista. Dominar o Comum por completo é dominar a Comunicação, inclusive a brecha de escape que o próprio sistema não dá conta de controlar uma vez que explica, mas não compreende seu processo. Logo, não é possível dominar o Comum por completo, mas é possível compreendê-lo (SALDANHA, 2016, p. 195).

É na brecha do "não controle" e do "não domínio hegemônico" que a Publicidade Social, que tratamos aqui, se posiciona. Vale, por isso, retomar outras correntes sobre a temática, para propormos uma concepção brasileira.

Apesar de continuar relacionado ao território físico, o conceito de comunidade não se limita mais a um "mero convivialismo num território, mas como o compartilhamento (ou uma troca)” (PAIVA et al., 2014), visto que a própria noção de território pode se expandir, em função das atuais configurações de espaço. Paralelamente à ressignificação territorial, as publicidades extrapolaram os centros comunitários (físicos ou virtuais) e avançaram para outras esferas da sociedade, ao mesmo tempo em que passaram a contar com sua participação para consumar o ato de tornar públicas novas formas de saber e de fazer. Assim, a Publicidade Social retoma seu sentido etimológico "tornar algo público" quando convida a sociedade civil para participar efetivamente de todo ou de parte do processo, desde formulação estratégica, passando pelas fases de criação e produção das campanhas publicitárias, até a implementação das ações. Ressaltamos que a Publicidade Social já acontecia na prática cotidiana das comunidades, realizada por seus membros, com participação ou não de agentes externos, mirando sempre no benefício para a própria localidade, independentemente de validações acadêmicas.

\section{Publicidade Social hegemônica do Norte Global}

Historicamente, os Estados Unidos inauguram a Publicidade Social para divulgar os Serviços Públicos que atenderiam às necessidades da população norte-americana. Essa linha está imbricada nas duas grandes guerras mundiais: por volta de 1917, o Committee of Public Information (CPI) 
foi criado pelo presidente norte-americano Woodrow Wilson, funcionando até 1919 e ajudando a propagar para a população o envolvimento do país na primeira grande guerra (LIMA, 2015). O CPI usava técnicas publicitárias para disseminar mensagens com ideais políticos através de cartazes, panfletos, filmes e conteúdos nos noticiários, que equiparavam o "ódio ao inimigo" ao "amor à pátria”, gerando nos cidadãos o desejo de contribuir para o sucesso da Nação.

Na época da Segunda Guerra Mundial, executivos dos meios de comunicação usaram técnicas publicitárias para divulgar serviços do governo. O propósito da nova categoria publicitária, na década de 1940, era mobilizar a indústria da propaganda para dar suporte aos esforços de guerra. Foi aí que o "Conselho Publicitário de Guerra” (antigo WAC) tornou-se "Conselho Publicitário" (Ad Council) e começou a direcionar o termo Publicidade Social não só para divulgar conteúdos das agências governamentais, mas para todos os tipos de anunciantes decididos a fortalecer a imagem institucional. Assim, nos "anos de 1950 as empresas atentaram para a importância da imagem institucional positiva e foi nessa época que a temática da Responsabilidade Social ganhou destaque" (SALDANHA, 2019). Na publicação Social Responsabilities of the Businessman, o economista americano Howard Bowen (1953, p. 6) destaca "the obligations of businessmen to pursue those policies, to make those decisions or to follow those lines of action which are desirable in terms of the objective and values of our society".

Segundo Kunsch (2003, p. 139), várias atualizações sobre o conceito foram pensadas desde então, inclusive as voltadas para o terceiro setor, com a implementação do balanço social como instrumento para monitoramento das organizações

capaz de demonstrar, por meio de indicadores sociais, o montante de investimentos das organizações em ações empreendidas em benefício do público interno, da cultura, da comunidade local e da sociedade como um todo. [...] uma prática adotada na França desde a década de 1970, fazendo parte até mesmo da legislação desse país (Lei n. 77.769, de 1997). 
As definições de responsabilidade social estão ligadas ao universo corporativo pois, pela "perspectiva moderna, a responsabilidade social passa a fazer parte da gestão das organizações” (KUNSCH, 2003, p. 138). Por isso, os gestores publicizam não só os investimentos em ações sociais, como também os respectivos resultados.

Ora, se a "responsabilidade social" está diretamente ligada aos atributos da gestão organizacional e a Publicidade Social norteamericana, diretamente ligada aos seus princípios, que paulatinamente ganharam contornos organizacionais, conclui-se que a vertente estadunidense usa temáticas sociais em suas comunicações publicitárias enquanto estratégia de valorização da imagem institucional positiva e atrativa para seus stakeholders.

Percebe-se aí uma deturpação do sentido originário da publicidade ("tornar algo público") que, enquanto comunicação pública, deveria por princípio disponibilizar dados referentes aos interesses públicos. Para Habermas (1997, p. 92), a emergência desses interesses está diretamente ligada à existência de um espaço de atuação dialógica na sociedade civil. O que o filósofo chamou de esfera pública seria um espaço ou "uma rede adequada para comunicação de conteúdos, tomadas de posição e opiniões”. No entanto, o frankfurtiano percebe que as alterações dos interesses publicizados nesses espaços passaram a se modificar de maneira cada vez mais sistemática, em função da pressão sofrida pelo mercado que, inclusive, passou a desenvolver leis para viabilizar a própria inserção na ambiência da produção cultural, para estrategicamente naturalizar os próprios valores para por "no lugar dessa argumentação, desse princípio de publicidade e dessa comunicação pública (Publizität) formas de comunicação cada vez mais inspiradas em um modelo comercial de 'fabricação de opinião'. Habermas vê nisso uma 'refeudalização da sociedade'" (MATTELART, 2000, p. 8).

A Publicidade Social norte-americana segue a trilha da "refeudalização da sociedade" habermasiana na mesma diretriz que a vertente espanhola. Ambas alinhadas ao Marketing Social, conceituado por Pringle e Thompson (2000, p. 3) como "ferramenta estratégica de marketing 
e de posicionamento que associa uma empresa ou marca a uma questão ou causa social relevante, $[. .$.$] uma forma de melhorar a imagem corpo-$ rativa, diferenciando produtos e aumentando tanto as vendas quanto a fidelidade."

Com base nas ideias defendidas por Moliner Tena em "Marketing social. La gestión de las causas” (1998), Emilio Feliu Garcia afirma que a publicidade social está para a publicidade assim como o marketing social está para o marketing, quando o produto é a própria causa social. Para Garcia (2004, p. 2), se "la publicidad es un instrumento del marketing dirigido a los públicos externos, podemos considerar la Publicidad Social como 'una extensión de la publicidad'."

O autor aponta para três maneiras de abordar "o social" na comunicação publicitária, "lo social' de la publicidad (función social de la publicidad); 'lo social' en la publicidad (publicidad con causa); la publicidad de 'lo social' (publicidad social)" (GARCIA, 2004, p. 3). Apesar de certa redundância entre os três itens, o tópico "função social da publicidade" leva em conta como as campanhas que contém "o social" como objeto se equiparam ao Marketing de Causas Sociais, pois seguem o estratagema do cobranding que, através de técnicas persuasivas de divulgação, fortalecem sua imagem institucional através das veiculações de publicidades que atrelam à marca o apoio às causas sociais em evidência. Enfim, Garcia reconhece a publicidade social pelo eixo norte-americano quando retoma suas origens em 1942, através do Ad Council, a nova categoria publicitária “[...]: la publicidad de servicio público (Public Service Advertising); su existencia, por tanto, data de una fecha muy anterior a la del Marketing social, que nacerá 'oficialmente' en 1971, con la publicación en el Journal of Marketing" (2004, p. 3).

O pesquisador conclui que os estudos sobre publicidade na Espanha são estritamente comerciais, inclusive pelas restrições das normas reguladoras da atividade "que ha hecho difícil el desarrollo de estudios sobre otras formas de publicidad, como la institucional, la política o la social. En estos campos existe todavía una considerable imprecisión conceptual que ha provocado, entre otras cosas, una gran confusión terminológica" 
(2004, p. 11). Em suma, tanto nos Estados Unidos quanto na Espanha, a publicidade social é definida a partir dos conteúdos corporativos sejam eles governamentais ou empresariais.

Das noções observadas no Norte Global, a que se aproxima da perspectiva latino-americana é a publicidade participativa que foi alavancada por pesquisadoras portuguesas em conjunto com pesquisas colombianas. Em 2018, o livro PartipanAd - Publicidad Participativa: una perspectiva global com un enfoque latinoamericano, organizado por Ana Duarte Melo e Marcela Duque, inspirado no tema do congresso IAMCR realizado na Colômbia no ano anterior, apresentou como proposta central, a problematização das relações paradoxais da indústria publicitária sem cair na cilada de demonizá-la, tampouco de limitar a discussão à divulgação de temáticas sociais. A ideia foi discutir contrapontos tais como "interesses privados vs. públicos, econômicos vs. culturais, corporativos vs. comunitários” (MELO; DUQUE, 2018, p. 9), sem enfraquecer o pensamento com posições maniqueístas.

Uma das divergências em relação à presente proposta são os pesos desiguais atribuídos aos extremos desses paradoxos. Apesar das pesquisas apresentadas apontarem para práticas interventivas, as discussões ainda usam como referência a visão das grandes corporações, visto que alguns exemplos usados nas discussões contemplam campanhas desenvolvidas por agências de publicidade globais. A vertente da Publicidade Cidadã trabalhada por Sara Balonas (2011) conflui, em certa medida, nosso enfoque de potencialização da participação cidadã.

É justo no terreno da participação, como veremos a seguir, que está a relevância da complexidade sobre o entendimento não "da", mas "de uma" hegemonia, já que "hegemonia não é algo unívoco; [...] suas próprias estruturas internas são altamente complexas, e têm de ser renovadas, recriadas e defendidas continuamente; e que do mesmo modo elas podem ser continuamente desafiadas e em certos aspectos modificadas" (WILLIAMS, 2005 [1973], p. 216).

Quando a participação social na construção comunicativa excede o limite das interações técnicas e fortalece sua condição vinculativa 
através do compartilhamento de um "nexo atrativo entre o si próprio e o outro" (SODRÉ, 2002, p. 223), há Publicidade Social, pois dilatam-se as possibilidades de transformação. O processo de dilatação resulta do engajamento cívico de novos atores que cooperam com saberes alternativos subvertendo, portanto, a lógica hegemônica das publicidades do mass media, e sugerem uma angulação contra-hegemônica para uma outra práxis publicitária, pois a "contra-hegemonia institui o contraditório e a tensão no que até então parecia uníssono e estável” (MORAES, 2010, p. 73).

A tensão é parte da mutação conceitual que, como dito anteriormente, prevê uma hibridização com o estabelecido, pois a "ruptura total nunca ocorre" (BACCEGA, 2010, p. 53). Logo, para chegarmos na noção de contra-hegemonia, partiremos da acepção de hegemonia gramsciana que afirma que "se a hegemonia é ético-política também é econômica; não pode deixar de se fundamentar na função decisiva que o grupo dirigente exerce no núcleo decisivo da atividade econômica" (GRAMSCI, 1968, p. 33). Logo, esses grupos deveriam ouvir os diversos atores sociais, para compreender "os interesses e as tendências dos grupos sobre os quais a hegemonia será exercida” e o lócus dessa interlocução seria a 'sociedade civil', o amálgama com nossa abordagem, cuja síntese conceitual será apresentada adiante.

A acepção de sociedade civil gramsciana está ligada à superestrutura e se compatibiliza com Williams (2005 [1973], p. 216), quando este argumenta que "só podemos entender uma cultura dominante e efetiva se entendermos o processo social do qual ela depende". Portanto, há que se refletir sobre as complexas relações da sociedade civil, para conjecturar as conexões da Publicidade Social latino-americana.

\section{Publicidade Social contra-hegemônica no Sul Global: uma proposta brasileira}

A sociedade civil está em atividade permanente, por conta da existência de processos mais flexíveis do que ideologias impostas, como é o caso 
dos movimentos sociais emergentes que reagem às imposições, ainda que residuais, dos saberes dominantes. Logo, é premente reconhecer

os significados e valores alternativos, as opiniões e atitudes alternativas, e até mesmo algumas visões de mundo alternativas, que podem ser acomodadas e toleradas no interior de uma determinada cultura efetiva e dominante. Isso tem sido muito pouco enfatizado em nossas noções de superestrutura, e mesmo em algumas noções de hegemonia (WILLIAMS, 2005 [1973], p. 216).

Todavia, mais importante do que reconhecer os modos alternativos, seria publicizá-los para potencializar uma inteligibilidade recíproca com outros saberes e pensamentos, a exemplo das possíveis junções entre os diferentes movimentos sociais. Esta potente articulação seria o caminho para a conversão de "práticas não hegemônicas em práticas contra-hegemônicas” (SANTOS, 2002, p. 266). Ou então, seria a confirmação do "epistemicídio, ou seja, a supressão dos conhecimentos locais perpetrada por um conhecimento alienígena (SANTOS; MENESES, 2009, p. 8).

A finalidade aqui não é ser uma contra-publicidade, mas um método que viabilize a saída do modo passivo. Sobretudo quando grupos subalternos reinventam técnicas com o material que têm em mãos ou se apropriam das tecnologias digitais, em princípio inalcançáveis, para reverberar comunicações que sensibilizem membros da sociedade civil em prol de suas reivindicações internas. Um exemplo foi o estúdio fotográfico itinerante feito de caixa de papelão e luz de led para registro, via smartphone, das cerâmicas expostas no e-commerce de Itaboraí, como será visto mais à frente. Sem apelações estéticas ou discursivas, intenta incluir e engajar agentes externos (PAIVA, 2003) para elaborações coletivas de planos tático-operacionais inovadores com ações interativas que vão desde abaixo-assinados (Ex.: Lei 7.835/2018), trabalho voluntário, doações em crowdfunding, guerrilhas, inovações gráficas, produções audiovisuais divulgadas em meios alternativos (@favelacineclube), eventos culturais (Festival Gastronômico Mangue na Mesa - Caravelas/ BA, Rodas culturais etc.) e, por fim, a partilha de um comum lídimo: 
o sentimento esperançoso das conquistas sociais e humanas, como será visto no quadro com alguns exemplos de casos e projetos nas considerações finais (SALDANHA, 2019).

Surgem novas propostas como a classificação mexicana², ou a "publicidade popular" identificada por investigadores colombianos da Unipanamericana Fundação Universitária como alternativa para elaboração de mensagens publicitárias

desde el diseño visual y la publicidad, y aquellas relacionadas con aspectos estéticos que vienen del pop art y del kitsch, y que son fundamentales en la concreción de la estrategia publicitaria: el mensaje, aspectos formales y estructurales, y la cultura, son solo algunos indicadores que pueden dar cuenta de la enorme riqueza simbólica que se encuentra en la publicidad popular (CORTÉS et al., 2018, p. 1).

Também em Bogotá, o projeto do "Centro de Memoria, Paz Y Reconciliación” (CMPyR) publicizou, em praças públicas, as vítimas do conflito armado na Colômbia através de performances intituladas "Para la guerra Nada. Ya no nos caben más muertos en la memoria” (20152016). O intuito foi fortalecer práticas cidadãs em defesa do processo de justiça transnacional. A iniciativa contou com professores, alunos, funcionários da Universidad de Bogotá Jorge Tadeo Lozano, além da participação dos moradores da cidade para consolidar a memória da tragédia humana (GUGLIELMUCCI et al., 2018).

Certamente existem iniciativas germinando no continente latino-americano, mas com pouca visibilidade em função da dificuldade de publicação científica sob a argumentação da fragilidade do objeto e produção de massa crítica sobre a temática. Nesse diapasão, o Brasil vem apresentando um esforço epistemológico para a área, inaugurado com a tipologia para Publicidade e Propaganda, onde a única menção

2 Campañas de imagen, de información, de atención, de prevención, incentivación a la acción inmediata, de sensibilización, de alteración de creencias, de promoción en la participación de actividades de responsabilidad cívica, de solicitud de apoyo a la sociedad frente a las contingencias naturales (FUENTES; ISLAS, 2018, p. 230). 
ao aspecto social está na classificação de Propaganda ideológica ${ }^{3}$ que, alinhada aos princípios das Relações Públicas, agrupa na "denominação de propaganda social todas as campanhas voltadas para as causas sociais: desemprego, adoção do menor, desidratação, tóxicos, entre outros. São programas que procuram aumentar a aceitação de uma ideia ou prática social em um grupo-alvo" (PINHO, 1990, p. 24).

Em relação à Publicidade, foi apresentado no VII Encontro de Pesquisadores em Publicidade e Propaganda (2017), um compêndio com a atualização das definições clássicas trabalhadas desde 1990 até 2016, considerando a articulação das obras referenciais da área (PINHO, 1990; LUPETTI, 2000; SANT'ANNA, 2015). Na sinopse, todas as tipificações ${ }^{4}$ referem-se à comunicação empresarial. Numa busca exploratória nos e-books ${ }^{5}$ do Encontro Nacional de Pesquisadores em Publicidade e Propaganda (PROPESQ), desde a primeira edição em 2010, evidencia-se a robustez dos estudos brasileiros em publicidade e propaganda, com extensa produção de temáticas inovadoras e um denso diálogo com a publicidade nacional e internacional. Todavia, a expressão "publicidade social” só é citada nas edições de 2016 e 2017, e em 2019, após a implementação do GT Publicidade Social, houve participação mais expressiva, ainda que incipiente. Seguindo na busca com o termo "marketing social”, verificou-se um aumento equilibrado das publicações e os textos com a palavra-chave "resistência" têm interface com estudos de identidade ou são ligados a alternativas tecnológicas. É notório que a literatura brasileira precisa se atualizar em relação à Publicidade Social, uma vez que as produções acadêmicas não acompanham o ritmo ou urgências dos movimentos sociais. Na prática, a comunicação publicitária se reinventa e intensifica seus pontos de contato com os consumidores que estão mais participativos. A partir do aumento do acesso a meios digitais

3 Sob as classificações: política; eleitoral; governamental; corporativa; legal; religiosa e a propaganda social.

4 Produto; serviço; varejo; comparativa; cooperativa; industrial, cooperativa; incentivo; promoção de vendas e promoção.

5 Disponível em: https://www.abp2.org/e-books. Acesso em: 26/01/2021. 
percebe-se uma considerável e progressiva ampliação da participação popular nas mais variadas ações de produção de conteúdo, que vão desde jogos e memes com posicionamentos políticos, como de spots com denúncias e divulgação de artistas regionais, até vídeos para divulgação de comércios locais [...] pode-se verificar, por exemplo, que a Publicidade Social $[\ldots]$ pode ser viabilizada por conta dos caminhos abertos pela ciberpublicidade. (SALDANHA; ATEM, 2015, p. 51).

A ciberpublicidade vem contribuindo estrategicamente para a expansão da Publicidade Social, de maneira que o cidadão comum gradualmente se desloca da posição de subalternidade e começa a participar criticamente das novas configurações do que deve se "tornar público”. Observa-se uma progressiva falência das táticas de apagamento das diferenças epistemológicas, culturais e políticas que serviram durante séculos à "missão colonizadora", cujo projeto era homogeneizar "o mundo, obliterando as diferenças culturais" (SANTOS; MENESES, 2009 , p. 8).

\section{Uma síntese da proposta brasileira}

Como fontes principais para fundamentação desta proposta, recorremos às leituras matriciais da comunicação social, aos artigos acadêmicos ${ }^{6} \mathrm{e}$ aos projetos desenvolvidos pelos próprios pesquisadores ${ }^{7}$ vinculados ao Laboratório de Investigação em Comunicação Comunitária e Publicidade Social (LACCOPS/UFF ${ }^{8}$ ). Também foram essenciais para robustez desta proposição, as consultas aos dados registrados nos diários de campo no decorrer das pesquisas empíricas norteadas pela pesquisa-ação,

6 A busca exploratória através da palavra-chave "publicidade social", de 2010 pra cá, foi feita em duas plataformas gratuitas de alto alcance: Google Acadêmico (maioria das produções de Portugal e Brasil) e Researchgate (com maioria dos textos em espanhol, apesar do termo de busca ter sido em português).

7 Formado por cinco professores na estrutura fixa e por uma média de quinze a vinte discentes circulantes entre egressos, pós-graduandos do Programa de Pós-Graduação em Mídia e Cotidiano (PPGMC/UFF) e de graduandos do curso de comunicação da Universidade Federal Fluminense (UFF). O credenciamento ocorre a cada dois anos.

8 Contemplado em 2019 pelo edital Grupo de Pesquisa Emergente da Fundação de Amparo à Pesquisa do Estado do Rio de Janeiro (FAPERJ). 
aos conteúdos difundidos na mídia hegemônica e às veiculações das mídias comunitárias nos períodos das realizações.

Elaboramos e produzimos ao longo da existência do Grupo de Pesquisa uma média de vinte projetos abarcando as cinco tipificações que serão apresentadas no quadro um, com a síntese conceitual. Em seguida ilustraremos, com pelo menos um exemplo, cada tipo de Publicidade Social. Parte das experiências que fundamentam esta reflexão foram realizadas pelo Laccops desde sua certificação pelo CNPq, em 2014. Todas se constituíram na relação dialógica e de confiança estabelecida desde o primeiro contato com os grupos parceiros.

A parceria é o alicerce que intensifica a "associação com uma ação ou com a resolução de um problema coletivo e no qual os pesquisadores e os participantes representativos [...] estão envolvidos de modo cooperativo ou participativo" (THIOLLENT, 2003, p. 14). Nessa perspectiva, o pesquisador precisa exercitar a escuta e estar aberto para atender as reais demandas. Por isso, a discussão exaustiva com os participantes dos projetos foi essencial para minimizar erros estéticos ou de linguagem, como a reprodução de estereótipos, e para deixar explícito que o protagonismo seria dos agentes locais.

Algumas técnicas de coleta de dados como entrevistas e rodas de discussão sobre os resultados parciais das ações referentes aos estudos e implementações práticas foram fulcrais nas tomadas de decisão. Participaram das etapas, os agentes locais, pesquisadores, alunos de graduação e de pós-graduação, sempre respeitando as deliberações específicas dos projetos em desenvolvimento. Em 6 anos de investigação teórica conjugada a projetos empíricos foi possível sistematizar uma tipologia de Publicidade Social, cujas tipificações se complementam organicamente e são exequíveis à realidade latina. 


\section{Quadro 1}

\begin{tabular}{|c|c|}
\hline \multicolumn{2}{|r|}{ Síntese Conceitual da Publicidade Social } \\
\hline Publicidade Social Comunitária & $\begin{array}{l}\text { Direcionada às comunidades de vida física com ações feitas na, pela e para a } \\
\text { comunidade, por agentes locais e com a participação de agentes externos. } \\
\text { Trabalha com práticas de "visibilidade positiva aos talentos (culturais, } \\
\text { artísticos, comerciais, alimentícios, científicos, etc) do lugar ou de um grupo } \\
\text { específico e tem por objetivo reverter os beneficios conquistados com as } \\
\text { ações para a própria coletividade, seja do lugar ou do grupo." (SALDANHA, } \\
\text { 2019). }\end{array}$ \\
\hline Publicidade Social Afirmativa & $\begin{array}{l}\text { Surge na Escola Popular de Comunicação Crítica (2005), projeto do } \\
\text { Observatório de Favelas (2000). Potencializa valores afirmativos com uso de } \\
\text { tecnologias digitais das comunidades que compartilham um 'comum' ligado } \\
\text { às demandas expressas em ações no espaço físico ou virtual e é livre do } \\
\text { "compromisso com a venda de produtos ou serviços" (Azevedo. 2015).Visa } \\
\text { divulgar atividades em territórios populares, além de dinamizar a economia } \\
\text { local. }\end{array}$ \\
\hline Publicidade Social de Causa & $\begin{array}{l}\text { Ligada às causas humanitárias e ambientais, se consolida na parceria com os } \\
\text { Movimentos Sociais e ONG's que retroalimentam reivindicações urgentes e } \\
\text { emergentes. Está em contínua atualização com as agendas das Instituições } \\
\text { intergovernamentais como a ONU, a OMS e a OMC para contribuir de } \\
\text { maneira criativa com as causas em evidência, com propostas positivas, em } \\
\text { larga escala. }\end{array}$ \\
\hline $\begin{array}{l}\text { Publicidade Social de Interesse } \\
\text { Público }\end{array}$ & $\begin{array}{l}\text { Se opõe à "Publicidade de Utilidade Pública" que faz parte da estrutura da } \\
\text { Comunicação Pública do Governo Federal, bem como compreende o } \\
\text { "interesse" público a partir do "lugar de escuta" e não pela imposição dos } \\
\text { interesses da classe dominante. Propõe resoluções legais para problemas } \\
\text { concretos que afetam a vida, a exemplo das questões ligadas aos Direitos } \\
\text { Humanos destacando os das minorias. }\end{array}$ \\
\hline Publicidade Social Transversal & $\begin{array}{l}\text { Nomenclatura definida pela publicitária e ativista Bruna Kassis, pode ter } \\
\text { alguma similaridade com a linha da Responsabilidade Social, uma vez que } \\
\text { também faz parte do planejamento estratégico das empresas. Entretanto, } \\
\text { transcende o aspecto da gestão quando o investimento social ultrapassa a } \\
\text { prestação de contas entre financiador e financiado, e equilibra a participação } \\
\text { poder público, empresas e agentes locais para viabilizar projetos de } \\
\text { transformação social. (SALDANHA, 2019) }\end{array}$ \\
\hline
\end{tabular}

Fonte: Saldanha (2021)

Na contrapartida das primeiras avaliações no cenário internacional, a proposta da Publicidade Social brasileira não se edifica apenas no fim (da divulgação, do "tornar público"), mas soma à prática da publicização, da construção coletiva incluindo a Sociedade Civil na idealização, na produção e na implantação de ações próprias desta categoria de Publicidade que caminha na contramão da lógica hegemônica, como pode ser observado no quadro a seguir: 
Quadro 2

\begin{tabular}{|c|c|}
\hline \multicolumn{2}{|r|}{ Exemplos de Projetos e Casos } \\
\hline Publicidade Social Comunitária & $\begin{array}{l}\text { "Levanta Caravelas-BA 2019!” https://www. facebook.com/soucaravelasbal, @soucaravelas, } \\
\rightarrow \text { Oficinas:audiovisual, redes sociais, gastronomia, plano estrtégico para a cidade. } \\
\rightarrow \text { Criação de brandbook para a cidade, produção de filmes, peças gráfias para os projetos } \\
\text { locais e criação das redes digitais de Caravelas } \\
\text { "Fevela Cineclube: Luz, Câmera, Revolução" (2016-2017) } \\
\rightarrow \text { impulsionou o aumento de } 200 \text { seguidores para mais de } 2.600 \text { (adultos e crianças) } \\
\rightarrow \text { Criaçăo da identidade visual e de todas redes do projeto }\end{array}$ \\
\hline Publicidade Social Afirmativa & $\begin{array}{l}\text { "É Nóix na Vida!!” (2020) } \\
\rightarrow \text { Favela do Jacarezinho, onde o isolamento social é utopia em tempos de Covid-19. } \\
\rightarrow \text { Campanha de informação para prevenção de contaminação à Covid-19 } \\
\rightarrow \text { Criação da identidade visual e peças veiculadas no Instagram e no whatsapp } \\
\end{array}$ \\
\hline Publicidade Social de Causa & $\begin{array}{l}\text { Produção teórica (2018) desenvolvido em parceria com Ousmane Thiam e Jossana Soares. } \\
\rightarrow \text { Objetivo:levantar a discussão sobre a causa da comunidade senegalesa de Niterói/RJ } \\
\rightarrow \text { A campanha para a marca "Dior Thiam", baseada na causa de refugiados e imigrantes, teve } \\
\text { como objetivo alavancar o negócio para garantir a autonomia do senegalês Ousmani Thiam na } \\
\text { cidade de Niterói. Desenvolvida pela Pares Cáritas-RJ e pelos próprios empreendedores: } \\
\text { @ dioroupaseacessorios; Facebook: Dior Roupas e Acessórios. }\end{array}$ \\
\hline Publicidade Social de Interesse Público & $\begin{array}{l}\text { Produção teórica (2018) para refletir sobre os impactos da publicidade na sociedade civil. } \\
\rightarrow \text { discutir o papel da Lei } 7.835 / 18 \text { decorrente de pressão popular para punição de campanhas } \\
\text { publicitárias do mass media que multa empresas cariocas que veiculam publicidades de cunho } \\
\text { misógino e sexista. A lei proibe "exposição, divulgação ou estimulo ao estupro e à violência } \\
\text { contra as mulheres" e as multas diárias vão de R\$ } 33 \text { mil a R\$ } 658 \text { mil. (BARREIRAS, 2018) }\end{array}$ \\
\hline Publicidade Social Transversal & $\begin{array}{l}\text { "Moldando o Futuro: Oficinas de comunicação em prol da sustentabilidade dos Oleiros de } \\
\text { Itaboraí" (2019-2021) - em andamento. } \\
\rightarrow \text { criação do e-commerce (site e redes) para que os Oleiros possam comercializar suas peças } \\
\text { (cerâmicas e artesanatos), com autonomia, sem depender exclusivamente de atravessadores. } \\
\rightarrow \text { Criação da identidade visual do projeto e das logomarcas das iniciativas dos agentes locais. } \\
\rightarrow \text { Construido em parceria entre a ONG Criar Brasil, o Laccops e os Oleiros de Itaborai. } \\
\rightarrow \text { Oficinas: planejamento estretégico, redação publicitária (perfis), fotografia (catálogo), } \\
\text { auviovisual. } \\
\rightarrow \text { O edital Luz Solidária é da Enel Brasil. }\end{array}$ \\
\hline
\end{tabular}

Fonte: Saldanha (2021)

\section{Considerações finais}

Compreendemos aqui por Publicidade Social uma nomenclatura guarda-chuva, com subdivisões ligadas ao "tornar público", estruturada em formatos colaborativos, interativos e participativos entre múltiplas vozes. No diagnóstico preambular, notou-se que na maioria das correntes existentes, reproduzem-se as mesmas técnicas e intenções da publicidade mercadológica, pois partem de um centro de poder, cujos princípios e crenças são difundidos para reforçar valores hegemônicos que beneficiam o mercado e de social só carregam o sobrenome. Ou seja, nos cenários do norte global, a nomenclatura não passa de uma técnica persuasiva que apela para sensibilização da opinião pública e assume, muitas vezes, uma postura oportunista, usando o assistencialismo como tática para o fortalecimento de uma reputação positiva para as organizações patrocinadoras. 
A intenção da perspectiva brasileira apresentada neste artigo é se estabelecer, através de produções criativas, elaboradas com materiais disponíveis em conjunto com as tecnologias de comunicação, principalmente os dispositivos móveis. O foco, porém, não está nos instrumentos em si, mas na forma de pensar e agir, na autonomia do interagente para redefinir novos modus operandi que dêem sentido à vida. Longe de estimular um aniquilamento gnoseológico, o novo saber deve impulsionar um ganho ontológico, pois tira o sujeito da condição de objeto inferiorizado, alçando-o a protagonista da situação.

\section{Bibliográficas}

AD COUNCIL, 2020. Our History. Disponível em: https://cutt.ly/6kukxir. Acesso em: 6 mai. 2020.

BACCEGA, M. A. Comunicação/educação: relações com o consumo. Importância para a constituição da cidadania. Comunicação, Mídia e Consumo, São Paulo, v. 7, n. 19, p. 49-65, jul. 2010.

BALONAS, S. O despertar da publicidade cidadã. Comunicação e Sociedade, Braga, v. 19, [s.n.], p. 127-143, 2011.

BARBERO, J. M.; BARCELOS, C. Comunicação e Mediações Culturais. Revista Brasileira de Ciência da Comunicação, São Paulo, v. 23, n. 1, p. 151-163, jan./jul., 2000.

BARREIRA, G. RJ cria lei que proíbe propaganda sexista e multa pode chegar a $\mathrm{R} \$ 1,3$ milhão. G1 Rio. Disponível em: https://glo.bo/2RwEWm9. Acesso em: 20 mai. 2020.

BOWEN, H. R. Social responsibilities of the businessman. New York, NY: Harper, 1953. CORTÉS, B.; GONZÁLEZ, Y.; CRUZ, J. Estrategias de publicidad popular en las plazas de mercado de la ciudad de Bogotá. CONGRESO DE LAASOCIACIÓN LATINOAMERICANA DE INVESTIGADORES DE LA COMUNICACIÓN, XIV, 2018. Costa Rica. Anais... Costa Rica, 2018, p. 227-232.

FUENTES,E.; ISLAS,L. La publicidad social en México, comprender su pasado y crear su futuro. Revista Ícone, Recife, v. 17, n. 2, p. 213-228, Mai., 2019.

GARCIA, E. F. La Publicidad Social. Repositorio Institucional de la Universad de Alicante. Disponível em: https://cutt.ly/ckulyL7. Acesso em: 22 jan. 2021.

GRAMSCI, A. Maquiavel, a Política e o Estado Moderno. Rio de Janeiro: Civilização Brasileira, 1989.

GUGLIELMUCCI, A.; SANTACRUZ, C; POSSO J. Para la guerra nada: publicidad y acción ciudadana em Bogotá sobre el conflicto armado colombiano. In: MELO, A., DUQUE, M. (Org.) ParticipAD. Participarory Advertising: a global perspective with a Latin American focus. Braga: Ed. CECS, 2018. p. 87-105.

HABERMAS, J. Direito e Democracia: entre facticidade e validade, volume II. Rio de Janeiro: Tempo Brasileiro, 1997. 
KUNSCH, M. Planejamento de relações públicas na comunicação integrada. São Paulo: Sumus, 2003.

LENIN, V. I. Working-Class and Bourgeois Democracy. In: Collected Works. Volume 8. Jan-Jul., 1905. Digital Reprints, 2009.

LIMA, W. 2015. EUA: quando a democracia é apenas uma parte do enredo. Disponível em: https://cutt.ly/ukulg42. Acesso em: 7 dez. 2020.

MATTELART, A.; MATTELART, M. História das teorias da comunicação. São Paulo: Loyola, 2000.

MELO, A.; DUQUE, M. ParticipAD. Participarory Advertising: a global perspective with a Latin American focus. Braga: Ed. CECS, 2018.

MORAES, D. Comunicação, hegemonia e contra-hegemonia: a contribuição teórica de Gramsci. Revista Debates, Porto Alegre, v. 4, n. 1, p. 54-77, jan.-jun. 2010.

PAIVA, Raquel. O Espírito Comum: Comunidade, Mídia e Globalismo. Rio de Janeiro: Mauad, 2003.

PAIVA, R., LACERDA, J., SALDANHA, P. INPECC investiga perfil dos estudos sobre comunidade na área da comunicação. COMPOS, XXIII, 2014, BELÉM/PA. Anais... Belém, 2014. p. 1-17.

PERUZZO, Cicília. Epistemologia e método da pesquisa-ação. Uma aproximação aos movimentos sociais e à comunicação. COMPOS, XXV, 2016, Goiânia/GO. Anais... Goiânia, 2016, p. 1-22.

PINHO, J. B. Propaganda Institucional: usos e funções da propaganda em relações públicas. São Paulo: Summus, 1990.

PRINGLE, M.; THOMPSON, H. Marketing Social para Causas Sociais e a Construção das Marcas. São Paulo: Makron Books. 2000.

SANT'ANNA, A.; JÚNIOR, I.; ROCHA, G.; DABUL, L. F. Propaganda: teoria, técnica e prática. São Paulo: Cengage Learning, 2015.

SALDANHA, P. Publicidade Social e sua tipificação: uma metodologia de transformação social. CONGRESSO BRASILEIRO DE CIÊNCIAS DA COMUNICAÇÃO, 42 , 2019, Belém. Anais... Belém: Intercom, 2019, v. 1, p. 1-15.

SALDANHA, P. "A ciência do comum”: a transcendência do Bios Midiático que reordena as vinculações cotidianas. Revista Latinoamericana de Ciencias de La Comunicación (ALAIC), v. 13, n. 25, p. 191-195. jul/dez. 2016.

SALDANHA, P.; ATEM, G. N. "centralidade" do consumidor e as novas interações com marcas globalizadas. Revista Espaço Acadêmico, n. 187, p. 48-59, dez. 2016.

SANTOS, B. Sociologia das ausências e das emergências. Revista Crítica de Ciências Sociais, 63, p. 237-280, out. 2002.

SANTOS, B.; MENESES, M. As Epistemologias do Sul. Coimbra: Edições Almedina SA, 2009.

SODRÉ, Muniz. Antropológica do espelho - uma teoria da comunicação linear e em Rede. Petrópolis: Vozes, 2002.

SODRÉ, Muniz. A Ciência do Comum: Notas para o Método comunicacional. Petrópolis: Vozes, 2015.

THIOLLENT, M. Metodologia da pesquisa-ação. São Paulo: Cortez, 2003. 
WILLIAMS, R. Base e superestrutura na teoria cultural marxista. Revista USP. São Paulo, n. 65, p. 210-224, mar.-maio 2005.

\section{Sobre a autora}

Patrícia Gonçalves Saldanha - Prof ${ }^{\mathrm{a}} \mathrm{Dr}^{\mathrm{a}}$ Associada II do Curso de Comunicação da Universidade Federal Fluminense, membro Permanente do PPGMC (Programa de Pós-graduação em Mídia e Cotidiano) e Coordenadora do Curso de Comunicação Social e Publicidade e Propaganda. Vice-Coordenadora (2012-2016) e Coordenadora (2016-2018) do GT de Cidadania do ALAIC, Coordenadora do Intercom Jr. Publicidade (2015) e Coordenadora do Intercom Jr. Cidadania (2016-2018). Fundadora e Líder do LACCOPS/CNPq (Laboratório de Investigação em Comunicação Comunitária e Publicidade Social) e membro fundadora do INPECC (Instituto Nacional de Pesquisa em Comunicação Comunitária). Mestrado (2003) e Doutorado (2009) em COMUNICAÇÃO E CULTURA pela Universidade Federal do Rio de Janeiro, Pós-doc em COMUNICAÇÃO E CULTURA (Publicidade Sensorial). Especializações com cursos de curta duração no Baruch College (NY/EUA). Graduação em Publicidade e Propaganda, com significativa experiência no mercado profissional e como docente em Universidades Públicas e Privadas.

Data de submissão: 12/09/2020

Data de aceite: 26/02/2021 